\title{
Self Concept Data
}

William C. Morse

$\mathrm{T}_{\mathrm{H}}$

HE University School Research Project of the School of Education (University of Michigan) is a three-year investigation sponsored by the U.S. Office of Education. It includes studies of aggression, how children formulate early coping-patterns, and the analysis of school classroom behavior.

One goal of the project is the development of schedules for classroom use which will add to the conventional knowledge now available to teachers. Most schools provide information on ability and achievements; some add measures of interests and personality. The additional classroom analyses suggested here are designed to provide indexes of the mental health climate, the learning focus, the pattern of group relationships, and the classroom social structure of a given classroom. The intent is to make this analysis possible, using only an hour of class time. Thus a teacher would be in a position to gauge the factors listed in addition to the traditional ability and achievement measures of pupils in a given classroom. Since previous research has shown that pupils, teachers, and observers live in separate school worlds, and that the perception of any one differs from the others, tools of this nature have direct utility in providing needed information on any classroom for the serious teacher. It would be doubly helpful for problem groups.

The teacher, of course, needs other information in addition to these indexes. Before one can understand a pupil's behavior, one needs to appreciate his particular pattern of motivation. Under the leadership of Dr. McKeachie, psychologists at the University of Michigan have conducted extensive basic research on classroom motivation in relationship to teaching styles. The University School Project is searching for some simplified methods to understand the dominant aspects of pupil motivation with the hope that it can be

William C. Morse is Professor of Educational Psychology, The University of Michigan, Ann Arbor. 
related to teaching style. Some students seek to cultivate interpersonal relationships more actively than they seek anything else the classroom offers. Others are involved primarily in achievement and orient themselves to accomplishing as much as possible relative to academic tasks. Still others have a politician's zest for influencing fellow classmates and bend their efforts in this direction. This makes a total of three need structures: affiliation, achievement, and influence. Now it is clear that a teacher appealing to the affiliation-motivated pupil with achievement-relevant stimulants is likely to have poor success. Teachers recognize, too, that certain pupils resist group activity, and the reason may be they see this as standing in the way of more direct achievement needs. Much of the work in a present-day classroom is confounded by these multiple and oftentimes opposed motivations found in individuals and subgroups. What is useful for one may be counter-indicated for others.

There is yet another area of pupil nature which has fundamental meaning for a teacher. This is the pupil's self-concept. Here we have what is perhaps the most salient clinical type of information for the educator. With knowledge about the "self", the teacher has a better chance to deal effectively with the moment-by-moment symptomatic behavior faced in classroom. With the self concept are bound up one's hopes, one's fears, and one's defenses.

In an effort to find a practical method for general school use in understanding a pupil's self concept, several methods were tried and two were put to extensive test. The Osgood Semantic Differential involves responses to a given stimulus through marking twenty-one sets of adjective scales. On each scale the pupil makes a check mark to indicate his position between the two adjectives. There were six stimuli. An example follows:

Myself (stimulus)

\begin{tabular}{|c|c|c|c|c|c|c|c|c|c|c|c|}
\hline Uncertain & 1 & 1 & / & 1 & I & 1 & 1 & 1 & 1 & 1 & Certain \\
\hline Pretend & I & 1 & & 1 & 1 & & I & / & 1 & / & True \\
\hline
\end{tabular}

(Twenty-one such adjectives sets are given for each stimulus presented.)

This method is designed to reduce defensive, "make myself look good" responses and at the same time to avoid difficulties of scoring found in more largely projective devices. 
The other major method of studying self-concept being currently explored is the Self-Esteem Inventory developed by Coopersmith. This contains fifty-eight items and the pupil makes a check mark in response to each. Two samples follow:

Like Me Unlike $\mathrm{Me}$

There are lots of things about myself

I'd change if I could

I'm proud of my school work.

This Self-Esteem Inventory has four subscales in addition to a lie scale ( 8 items). These subscales are self (26 items), social (8 items), home, (8 items) and school (8 items). After preliminary study and difficulty in use, the lie scale was dropped. Since we were interested in school rather than home phenomena, this sub scale was also eliminated.

It is as yet too early to know which of the two methods of response will be more useful for school study of the pupil self-concept, because the real value will be in predictive ability for a teacher in anticipating important things about pupils' behavior. But the startling thing to us was the openness of pupils about their selffeelings on the Self-Esteem Inventory. And the situation, as they perceive it, certainly makes any educator who is concerned with mental health uneasy about the state of affairs.

In addition to information from pupils in the University School it is our good fortune, through collaborators in research, to have data from a metropolitan school system with pupils from all strata of society. This has enabled us to analyze the responses from over 600 pupils, in alternate grades from three through eleven. What do we find if we employ self esteem as an index of mental health?

While the complete report is too complicated for a brief analysis, certain things stand out. First there is a drop on "self", and "school self" between grades three and five. Recovery starts with grade seven and by grade eleven both "self" and "social self" are back up to or better than grade three. However, with "school self", the drop between grades three and five is the most pronounced and there is no pattern of recovery. The mean satisfaction is lower on "school self' than either of the other two. 
But the impact is not clear until one looks at the individual items and the manner in which the pupils respond to them.

Of the fifty-six items, twenty-six items make up the "self" scale. On this scale all but two items produce over 10 per cent negative responses about the self. Even on these two about 10 per cent of all the pupils express a very negative self-image. Self-report instruments are always subject to interpretation. What does a response mean? Are they really honest? Won't the pupils be defensive? Of course any self-report is subject to various limitations. Pupils may be defensive, give stereotyped replies, or just lie. The test has been found previously to be reliable, and conversations with a small sample of the pupils giving low responses suggests fairly honest reporting. If this is defensive, it is unusual that pupils should go out of their way to look bad. It may well be that the actual number of discouraged pupils is much higher.

Many of the items show a decrease in self esteem with age. For example, to "I feel pretty sure of myself," 12 per cent of the third graders say "unlike me," while 34 per cent of the eleventh graders make that response. Again, 44 per cent of the eleventh graders often wish they were someone else. Almost a third of all the pupils see themselves as "giving in" very easily, and say "it's pretty tough to be me," while 25 per cent of them feel that things are all mixed up in their lives, and have a low opinion of themselves. As many as 8 per cent of the high school students consider themselves failures, but even a higher percentage of the younger children feel this way.

\section{School EsTEEM}

With such low personal esteem, what of their school self esteem? Is school an oasis? We already have reason to doubt from the overall picture of this dimension's scores. The general impression one gets is that for the young child, school is a secure place with regard to mental health, but as he grows older this confidence diminishes. While some items tend to stay the same over the grades, many change for the worse. Eighty-four per cent of the third graders are proud of their school work, while only 53 per cent of the eleventh graders are. In the low grades, 93 per cent feel they are doing the best work they can; only 37 per cent of the oldest pupils feel this way. Regardless of their achievement quotients and the fact that the failures tend to drop out, the pupils who remain in school come to feel that they are doing inadequate work. Again, 
over half of the young pupils say that they are doing as well in school as they would like, but only 22 per cent of the eleventh graders feel this way. About 40 per cent of pupils at all ages of ten feel upset in school; with regard to achievement 20 per cent say their teacher makes them feel "not good enough", and these items stay virtually the same with age. Over 40 per cent report they often become discouraged in school, and this increases with age from 22 per cent to forty three per cent.

\section{A Sense of Personal Failure}

While neither the self-picture nor the school self-esteem is pleasant, the school self appears to be the more negative. Whatever else we have done, we have communicated a sense of personal failure to many of our pupils. In general, the longer we have them, the less favorable things seem to be. There are probably plenty of good rationalizations to take the sting out of these findings. Some educators have said that all this shows is that we have raised the sights of our pupils with regard to school performance. This hardly seems enough, when the other self-scores do not follow this pattern. The fact remains, if we care about the pupil's self-regard, we have much work to do. We need to know more about the nature of our pupils through the years. Much of their energy is now being devoted to handling their sense of failure which could better be devoted positively to school effort. Pupils with such anxieties are of course harder to teach.

As our research progresses, we hope to be able to see how these self feelings develop and how they bear on such other aspects of the school setting as achievement and social behavior. At the present time, factor analysis and interrelationships of these scores with other data from the total study are in the process of analysis. The packet of scales with norms for classroom analysis should be available soon. 